\title{
REVISED Comments about the appraisal of systematic reviews in
}

\section{restorative dentistry [version 3; peer review: 2 approved, 1}

\section{approved with reservations]}

\author{
Kelvin I. Afrashtehfar (D1) 1-3, Musab H. Saeed (iD)1 \\ ${ }^{1}$ Division of Restorative Dental Sciences, Clinical Sciences Department, Ajman University, Ajman, P.O. Box 346, United Arab Emirates \\ ${ }^{2}$ Department of Reconstructive Dentistry and Gerodontology, School of Dental Medicine, University of Bern, Berne, BE, 3010, \\ Switzerland \\ ${ }^{3}$ Centre of Medical and Bio-allied Health Sciences Research, Ajman University, Dubai, City of Gold, United Arab Emirates
}

V3 First published: 03 Jun 2021, 10:442

https://doi.org/10.12688/f1000research.53117.1

Second version: 24 Nov 2021, 10:442

https://doi.org/10.12688/f1000research.53117.2

Latest published: 23 Feb 2022, 10:442

https://doi.org/10.12688/f1000research.53117.3

\section{Abstract}

Adequate adoption of evidence-based practice is deeply rooted in accessing methodological quality and completeness of systematic reviews and meta-analyses reporting. Nonetheless, this assumption might be flawed if the methodological quality assessment has not been properly conducted. Taking the former statement into consideration, this correspondence article encourages the improvement of future tertiary manuscripts, especially in the field of restorative dentistry. Thus, this article addresses an overview of reviews in restorative dentistry as an example of evaluating tertiary evidence for increasing the awareness of reviewers, authors, and readers.

Keywords

data management, dentistry, evidence-based medicine, evidencebased practice

This article is included in the Research on

Research, Policy \& Culture gateway.

\section{Open Peer Review}

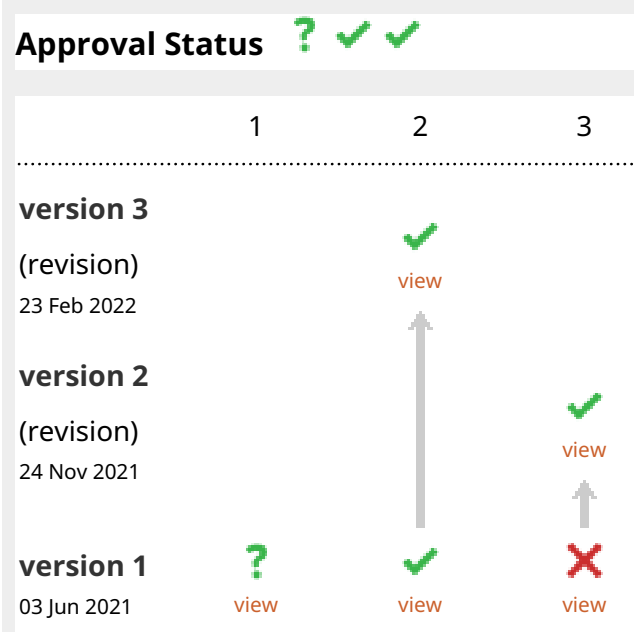

1. Marta Roqué-Figuls (D), Biomedical

Research Institute Sant Pau (IIB Sant Pau),

Barcelona, Spain

2. Luca Testarelli, Sapienza University of Rome, Rome, Italy

Rodolfo Reda (D), Sapienza University of Rome, Rome, Italy

\section{Spyridon N. Papageorgiou (D), University of}

Zurich, Zurich, Switzerland

Any reports and responses or comments on the article can be found at the end of the article. 
Corresponding authors: Kelvin I. Afrashtehfar (kelvin.afrashtehfar@unibe.ch), Musab H. Saeed (m.saeed@ajman.ac.ae)

Author roles: Afrashtehfar KI: Conceptualization, Data Curation, Formal Analysis, Funding Acquisition, Investigation, Methodology, Project Administration, Resources, Software, Supervision, Validation, Visualization, Writing - Original Draft Preparation, Writing - Review \& Editing; Saeed MH: Funding Acquisition, Project Administration, Resources, Visualization, Writing - Review \& Editing

Competing interests: No competing interests were disclosed.

Grant information: The author(s) declared that no grants were involved in supporting this work.

Copyright: ( $) 2022$ Afrashtehfar KI and Saeed MH. This is an open access article distributed under the terms of the Creative Commons Attribution License, which permits unrestricted use, distribution, and reproduction in any medium, provided the original work is properly cited.

How to cite this article: Afrashtehfar $\mathrm{KI}$ and Saeed $\mathrm{MH}$. Comments about the appraisal of systematic reviews in restorative dentistry [version 3; peer review: 2 approved, 1 approved with reservations] F1000Research 2022, 10:442

https://doi.org/10.12688/f1000research.53117.3

First published: 03 Jun 2021, 10:442 https://doi.org/10.12688/f1000research.53117.1 


\section{REVISED Amendments from Version 2}

The text has been revised to make it sound more neutral. Also, some orthographic errors have been amended.

We have included mention of Embase and Medline to support this correspondence article.

The reference list has been updated to show the breadth and depth of the subject and the expertise of the authors in the topic related to research synthesis, which includes systematic review and umbrella review methods.

Dr. Musab Hamed Saeed, Associate Professor at Ajman University, UAE, contributed to the Funding Acquisition, Project Administration, Resources, and Writing - Review \& Editing of this new version. Thus, he has been added to the author list; the article text has been modified to acknowledge the plurality of the authors throughout this new version.

"Vicerrectorado de Investigación, Universidad Católica San Antonio de Murcia, Murcia, 30107, Spain" has been removed from the affiliations because the work conducted during this study was not associated with this institute.

Any further responses from the reviewers can be found at the end of the article

\section{Comments about the appraisal of systematic reviews in restorative dentistry}

Dear respectable Advisory Editors and readers:

The publication by Sarkis-Onofre et al. ${ }^{1}$ "Systematic reviews in restorative dentistry: discussing relevant aspects," in the Journal of Esthetic and Restorative Dentistry in the May 2019 issue was read with great and particular interest. This well-written overview of reviews or systematic review of systematic reviews stated that "This study was not registered in PROSPERO" since PROSPERO indicates that "Reviews of methodological issues need to contain at least one outcome of direct patient or clinical relevance in order to be included in PROSPERO." Interestingly, despite the fact that the above referenced tertiary study falls in the PROSPERO's review of reviews category, it was neglected to being classified as such. Additionally, if PROSPERO was not an option, the a priori protocol could have been easily registered in another repository. Therefore, the authors' arguments not to register their protocol in PROSPERO are not valid.

Moreover, the authors ${ }^{1}$ mentioned that the previous version of their review ${ }^{2}$ has a protocol available upon request. However, their first paper $^{2}$, which is in a Brazilian University Magazine printed in Portuguese language, does not support the updated version of the review properly since their first version does not consider any protocol in the text.

Their critical appraisal using AMSTAR-2 appears in Table 2. Five out of the 16 included review studies in their review of reviews, had between one to four AMSTAR-2 items referred as "Authors reported different information by e-mail however, it was not found in the article." This reporting method may not be the most scholarly or safest to present their findings, especially when the authors of their included review studies kindly accepted to provide further clarification about their methodology.

Particularly, the first author of Afrashtehfar et al. ${ }^{3}$ "Failure rate of single-unit restorations on posterior vital teeth: a systematic review" regretted the online communication with their corresponding author when he was requested to provide further information. Perhaps Sarkis-Onofre et al. should have dedicated more time to conduct an adequate assessment ${ }^{4}$. For example, their unfavorable categorization of the AMSTAR-2 items 4, 7, and 16 for Afrashtehfar et al. ${ }^{3}$ may be mistaken. A comprehensive literature search (item 4) can be considered in the former paper $^{3}$ since it searched for published papers for over 20 years with no language restriction, using four electronic databases (including Embase and Medline via Ovid) and displaying each search strategy in the Appendix section. Additionally, the review hand searched eight journals and also screened manually in the reference list of all identified relevant primary studies and related secondary studies ${ }^{3}$. Next, the list of excluded primary studies and justifications (item 7) were provided in Supplemental Table 6 (i.e., full-text excluded articles and reasons for exclusion). Regarding any potential sources of conflict (item 16), it is well-stated on the first page of the review that this study was "Supported in part by a Knowledge Transfer Grant from the Network for Oral and Bone Health Research." Additionally, there is a section at the end of the paper for Acknowledgements where librarians and statisticians were thanked for their consultancy ${ }^{3}$.

Moreover, the search and eligibility criteria for Sarkis-Onofre et $a l^{1}{ }^{1}$ were systematic reviews that met PRISMA-P, including adults over 18 years of age with direct composite resin restoration in posterior teeth compared with other materials or techniques used in posterior teeth regardless of the outcome up to October $15^{\text {th }}, 2017$. However, some articles that fully suited their inclusion criteria were not included. For example, Afrashtehfar et al. "Failure of single-unit restorations on root filled posterior teeth: a systematic review" was not included despite being available from November 21 st, 2016. Therefore, their search strategy and their search conduct (including the elimination of duplicates $)^{6}$, as well as screening ${ }^{7}$, raise some serious methodological concerns ${ }^{8}$.

Their overview of reviews has a collaboration with well-known evidence-based medicine experts from Canada, Tricco and Moher', which usually rely on the talent from their research team for screening and assessing the literature.

After a brief analysis, this letter encourages the improvement of future synthesis of studies including their quality assessment to:

- Address clarification with authors of potentially included studies safely and respectfully to avoid accusation, especially if there is no consensus on the matter from different experts (i.e., two experts as a minimum) $)^{10-15}$.

- Take the time and effort necessary to assess the review paper of interventions according to AMSTAR-2 ${ }^{4}$. At 
least two experts in the field should also determine this instead of two research trainees.

- Spend sufficient time with expert librarians to develop an adequate search strategy in multiple databases ${ }^{3,5}$.

- Use a reference manager and do not rely on removing the duplicates by selecting only one category (i.e., authors' names). Thus, the available categories should be combined to avoid removing records that may share the same publication journal, year, or authors.

- A PRISMA checklist ${ }^{16,17}$ should be submitted, reporting compliance with each item by indicating the paragraph and page where they can be identified in the review/ appraisal. All the required reporting should be included in the quality assessment to ensure transparency and validity.
Data availability

Underlying data

No data are associated with this article.

\section{Authorship contribution based on the ICMJE criteria}

Kelvin Ian Afrashtehfar: Conceptualization, Data Curation, Formal Analysis, Funding Acquisition, Methodology, Project Administration, Resources, Writing - Original Draft Preparation, Writing - Review \& Editing.

Musab Hamed Saeed: Funding Acquisition, Project Administration, Resources, Writing - Review \& Editing.

\section{Acknowledgements}

The authors thank Ajman University for supporting the publication of the present article.
1. Sarkis-Onofre R, Pereira-Cenci T, Tricco AC, et al.: Systematic reviews in restorative dentistry: discussing relevant aspects. J Esthet Restor Dent. 2019; 31(3): 222-232.

PubMed Abstract | Publisher Full Text

2. Aquino A, Dias C, Almeida F, et al.: Características de reporte e condução de revisões sistemáticas que avaliaram a longevidade de restaurações de resina composta em dentes posteriores. Revista Da Faculdade De Odontologia UPF. 2017; 22(1): 25.

Publisher Full Text

3. Afrashtehfar KI, Emami E, Ahmadi M, et al.: Failure rate of single-unit restorations on posterior vital teeth: A systematic review. J Prosthet Dent 2017: 117(3): 345-353.e348.

PubMed Abstract | Publisher Full Text

4. Shea BJ, Reeves BC, Wells G, et al.: AMSTAR 2: a critical appraisal tool for systematic reviews that include randomised or non-randomised studies of healthcare interventions, or both. BMJ. 2017; 358: j4008. PubMed Abstract | Publisher Full Text | Free Full Text

5. Afrashtehfar KI, Ahmadi M, Emami E, et al.: Failure of single-unit restorations on root filled posterior teeth: a systematic review. Int Endod J. 2017; 50(10): 951-966.

PubMed Abstract | Publisher Full Text

6. Kwon Y, Lemieux M, McTavish J, et al.: Identifying and removing duplicate records from systematic review searches. J Med Libr Assoc. 2015; 103(4): 184-188.

PubMed Abstract | Publisher Full Text | Free Full Text

7. McGowan J, Sampson M: Systematic reviews need systematic searchers. J Med Libr Assoc. 2005; 93(1): 74-80. PubMed Abstract | Free Full Text

8. Pussegoda K, Turner L, Garritty C, et al:: Systematic review adherence to methodological or reporting quality. Syst Rev. 2017; 6(1): 131 PubMed Abstract | Publisher Full Text | Free Full Text

9. Moher D, Tricco AC: Issues related to the conduct of systematic reviews: a focus on the nutrition field. Am J Clin Nutr. 2008; 88(5): 1191-1199. PubMed Abstract
10. Hasanzade M, Aminikhah M, Afrashtehfar KI, et al.: Marginal and internal adaptation of single crowns and fixed dental prostheses by using digital and conventional workflows: A systematic review and meta-analysis. J Prosthet Dent. 2021; 126(3): 360-368.

PubMed Abstract | Publisher Full Text

11. Afrashtehfar KI, Del Fabbro M: Clinical performance of zirconia implants: A meta-review. J Prosthet Dent. 2020; 123(3): 419-426. PubMed Abstract | Publisher Full Text

12. Afrashtehfar KI, Katsoulis J, Koka S, et al.: Single versus splinted short implants at sinus augmented sites: A systematic review and metaanalysis. J Stomatol Oral Maxillofac Surg. 2021; 122(3): 303-310. PubMed Abstract | Publisher Full Text

13. Hasanzade $\mathrm{M}$, Shirani $\mathrm{M}$, Afrashtehfar $\mathrm{KI}$, et al.: In vivo and in vitro comparison of internal and marginal fit of digital and conventional impressions for full-coverage fixed restorations: a systematic review and meta-analysis. J Evid Based Dent Pract. 2019; 19(3): 236-254. PubMed Abstract | Publisher Full Text

14. Del Fabbro M, Afrashtehfar KI, Corbella S, et al.: In vivo and in vitro effectiveness of rotary nickel-titanium vs manual stainless steel instruments for root canal therapy: systematic review and meta-analysis. J Evid Based Dent Pract. 2018; 18(1): 59-69. PubMed Abstract | Publisher Full Text

15. Afrashtehfar KI, Afrashtehfar CD: Lack of association between overload and peri-implant tissue loss in healthy conditions. Evid Based Dent. 2016; 17(3): 92-93.

PubMed Abstract | Publisher Full Text

16. Moher $D$, Shamseer $L$, Clarke $M$, et al.: Preferred reporting items for systematic review and meta-analysis protocols (PRISMA-P) 2015 statement. Syst Rev. 2015; 4(1): 1.

PubMed Abstract | Publisher Full Text | Free Full Text

17. Liberati A, Altman DG, Tetzlaff J, et al.: The PRISMA statement for reporting systematic reviews and meta-analyses of studies that evaluate health care interventions: explanation and elaboration. PLoS Med. 2009; 6(7): e1000100. PubMed Abstract | Publisher Full Text | Free Full Text 


\section{Open Peer Review}

\section{Current Peer Review Status:}

\section{Version 3}

Reviewer Report 28 February 2022

https://doi.org/10.5256/f1000research.121499.r124764

(C) 2022 Testarelli $\mathbf{L}$ et al. This is an open access peer review report distributed under the terms of the Creative Commons Attribution License, which permits unrestricted use, distribution, and reproduction in any medium, provided the original work is properly cited.

\section{Luca Testarelli}

Department of Oral and Maxillofacial Sciences, School of Dentistry, Sapienza University of Rome, Rome, Italy

\section{Rodolfo Reda}

Department of Oral and Maxillofacial Sciences, School of Dentistry, Sapienza University of Rome, Rome, Italy

We believe that the article no longer presents any criticism, it is well written and complete.

Competing Interests: No competing interests were disclosed.

Reviewer Expertise: $\mathrm{CBCT}$, Dental Imaging, Endodontics, Oral Microbiology, Oral Surgery.

We confirm that we have read this submission and believe that we have an appropriate level of expertise to confirm that it is of an acceptable scientific standard.

\section{Version 2}

Reviewer Report 26 January 2022

https://doi.org/10.5256/f1000research.79657.r101051

(C) 2022 Papageorgiou S. This is an open access peer review report distributed under the terms of the Creative Commons Attribution License, which permits unrestricted use, distribution, and reproduction in any medium, provided the original work is properly cited.

\section{Spyridon N. Papageorgiou}

${ }^{1}$ Clinic of Orthodontics and Pediatric Dentistry, Center of Dental Medicine, University of Zurich, 
Zurich, Switzerland

2 Clinic of Orthodontics and Pediatric Dentistry, Center of Dental Medicine, University of Zurich, Zurich, Switzerland

My comments to the content of the piece have been covered.

Competing Interests: No competing interests were disclosed.

Reviewer Expertise: Orthodontics; evidence-based dentistry; systematic reviews

I confirm that I have read this submission and believe that I have an appropriate level of expertise to confirm that it is of an acceptable scientific standard.

\section{Version 1}

Reviewer Report 16 November 2021

https://doi.org/10.5256/f1000research.56469.r93586

(C) 2021 Papageorgiou S. This is an open access peer review report distributed under the terms of the Creative Commons Attribution License, which permits unrestricted use, distribution, and reproduction in any medium, provided the original work is properly cited.

\section{Spyridon N. Papageorgiou}

${ }^{1}$ Clinic of Orthodontics and Pediatric Dentistry, Center of Dental Medicine, University of Zurich, Zurich, Switzerland

${ }^{2}$ Clinic of Orthodontics and Pediatric Dentistry, Center of Dental Medicine, University of Zurich, Zurich, Switzerland

${ }^{3}$ Clinic of Orthodontics and Pediatric Dentistry, Center of Dental Medicine, University of Zurich, Zurich, Switzerland

I read with interest the abovementioned submission. However, I must say that I am somewhat confused since the author used this piece to comment on inadequacies, as deemed by the author, of a JERD-published overview of reviews that also included one of his SRs. In essence, this piece is not thought of as a standalone paper but is rather aimed at the already published overview like a correspondence with points to be addressed by the authors of the original overview in JERD. Therefore, I believe this would be more appropriate to be submitted as such in JERD and not here (not to mention that it is significantly more probable that it will be read and will be replied upon by the overview authors). Thanks for letting me see this.

Specific comments

1. Abstract. "accessing" is probably "assessing".

2. Bear in mind that methodological quality is different from the risk of bias. I'm not sure which of the two you are implying here, but it makes sense that it is the latter. 
3. "The improvement of future methodological quality assessment manuscripts": this needs to be reformulated more succinctly.

4. "Thus, this article addresses a methodological quality assessment about systematic reviews in restorative dentistry by Sarkis-Onofre et al. in the May 2019 issue of the Journal of Esthetic and Restorative Dentistry as an example of evaluating appraisals of reviews for increasing the awareness of reviewers, authors, and readers." Instead of relaying what this piece does, better relay its' scope/aim and its final recommendations.

5. Text. The cited paper is neither "methodological quality assessment of systematic reviews" (methodological quality assessment is a procedure) nor a "systematic review of systematic reviews" - a systematic review addresses a clinically-based research question, ideally based on PICO. The cited paper is an overview of systematic reviews.

6. The point about lack of registration in PROSPERO is a valid one, according to Sarkis-Onofre et al., since it complies with the instructions of PROSPERO. However, all studies that have an a priori protocol can register it (and benefit from this) and many different appropriate repositories exist.

7. I'm not sure what is the point about the protocol being mentioned but not given. It doesn't matter what the authors say: if there is no publicly available registered/time-stamped protocol, there is none.

8. Likewise, I'm not sure what is meant with the $3^{\text {rd }}$ paragraph. Information provided through e-mails might not necessarily be regarding the same way as published information, but can still be used in a scientific publication, if deemed appropriate.

9. The paragraph about the Sarkis-Onofre et al. authors wrongly judging some AMSTAR 2 fields of your SR seem to be valid, however.

10. Likewise, the comment about potentially missed SRs to include seems to be valid.

11. The last bullet point might not necessarily be correct, since PRISMA is meant for systematic review -it is not a reporting guideline for overviews of review (though some fields of it might be adopted with modifications).

Is the rationale for commenting on the previous publication clearly described? Yes

Are any opinions stated well-argued, clear and cogent? Partly

Are arguments sufficiently supported by evidence from the published literature or by new data and results?

No

Is the conclusion balanced and justified on the basis of the presented arguments? 
Competing Interests: No competing interests were disclosed.

Reviewer Expertise: orthodontics; evidence-based dentisty; systematic reviews

I confirm that I have read this submission and believe that I have an appropriate level of expertise to state that I do not consider it to be of an acceptable scientific standard, for reasons outlined above.

Author Response 16 Nov 2021

\section{Kelvin Afrashtehfar}

Dr. Papageorgiou is thanked for his contribution after the correspondence author suggested him as a reviewer.

The correspondence author is glad to answer his comments and clear any confusion Dr. Papageorgiou has referred to.

The overview authors will be invited to reply to the correspondence author comment upon completion. As the reviewer may know, some dental journals do not accept letters to the Editor. JERD does not accept replica or letters to the Editor, whereas F1000Research provides the opportunity to have this correspondence open to the public free of charge. Thus, the latter is a different option and could be considered, by some researchers, an ideal journal to allocate the correspondence comment.

Reply to the main specific comments:

The correspondence author agrees with Dr. Papageorgiou that methodological quality assessment is not the same as the risk of bias. However, the correspondence author must say that an "overview of systematic reviews" is the same as a "systematic review of systematic reviews." Kindly refer to Pollock M, Fernandes RM, Becker LA, Pieper D, Hartling L. Chapter V: Overviews of Reviews. In: Higgins JPT, Thomas J, Chandler J, Cumpston M, Li T, Page MJ, Welch VA (editors). Cochrane Handbook for Systematic Reviews of Interventions version 6.2 (updated February 2021). Cochrane, 2021. Available from www.training.cochrane.org/handbook.

The correspondence author does understand that PROSPERO is probably the most popular repository among many other available options. Indeed, the correspondence author did refer to PROSPERO as the cited paper did. In fact, the correspondence author quoted their statement. The correspondence author appreciates that Dr. Papageorgiou found valid the point concerning the lack of PROSPERO registration.

The point of mentioning PROSPERO is supported by AMSTAR-2, which considers "protocol registered before start of review" as a critical domain. Please refer to Shea BJ, Reeves BC, Wells G, Thuku M, Hamel C, Moran J, Moher D, Tugwell P, Welch V, Kristjansson E, Henry DA. AMSTAR 2: a critical appraisal tool for systematic reviews that include randomised or non- 
randomised studies of healthcare interventions, or both. BMJ 2017; 358: j4008. Thus, one would expect that an overview of reviews (or systematic review of systematic reviews) should avoid missing such critical domain that they have assessed in their study where they used systematic reviews as the analytic unit.

The correspondence author thanks Dr. Papageorgiou for all the other comments that he found valid. For instance, the overview is missing to include SRs, review authors wrongly judging some AMSTAR-2 fields of a previous SR by the correspondence author, and lack of repository registry.

Lastly, the author appreciates Dr. Papageorgiou's comments regarding this correspondence comment. The points that could be perceived as a disagreement have been addressed by the correspondence author here.

Competing Interests: No competing interests were disclosed.

Reviewer Report 15 October 2021

https://doi.org/10.5256/f1000research.56469.r92392

(c) 2021 Testarelli L et al. This is an open access peer review report distributed under the terms of the Creative Commons Attribution License, which permits unrestricted use, distribution, and reproduction in any medium, provided the original work is properly cited.

\section{Luca Testarelli}

${ }^{1}$ Department of Oral and Maxillofacial Sciences, School of Dentistry, Sapienza University of Rome, Rome, Italy

2 Department of Oral and Maxillofacial Sciences, School of Dentistry, Sapienza University of Rome, Rome, Italy

3 Department of Oral and Maxillofacial Sciences, School of Dentistry, Sapienza University of Rome, Rome, Italy

\section{Rodolfo Reda}

1 Department of Oral and Maxillofacial Sciences, School of Dentistry, Sapienza University of Rome, Rome, Italy

2 Department of Oral and Maxillofacial Sciences, School of Dentistry, Sapienza University of Rome, Rome, Italy

3 Department of Oral and Maxillofacial Sciences, School of Dentistry, Sapienza University of Rome, Rome, Italy

The evaluations reported in this article are of high quality and demonstrate a great knowledge of the literature and of the analysis of articles present in this article thanks to the reporting items and quality assessments. 
The author underlines in this commentary his criticisms of the review under consideration and makes suggestions for improving the methodology and reporting of this kind of research. The author appears to be involved in Sarkis-Onofre's research, and this limits his field of action in contesting the execution of the study, underlining how another research of his has been excluded. However, we believe that the criticisms raised go beyond the conflict of interest and can be considered valid.

As described by the author, we agree with the need for more transparency on the methodology of these studies.

Regarding the registration on PROSPERO, we believe that this kind of revision remains valid regardless of this. The contestation of the protocol used by the author, rather than leading to the use of standardized protocols, we believe is necessary that it be well described in the article and that it be available upon request by the authors of the study.

The criticisms that are posed in the article, we believe are valid and well structured. The bibliography that underlies them is thick and published in high-level journals. We, therefore, consider this article suitable for indexing, sure of the fact that it can be an added value for the quality of this type of research.

Is the rationale for commenting on the previous publication clearly described?

Yes

Are any opinions stated well-argued, clear and cogent?

Yes

Are arguments sufficiently supported by evidence from the published literature or by new data and results?

Yes

Is the conclusion balanced and justified on the basis of the presented arguments? Yes

Competing Interests: No competing interests were disclosed.

Reviewer Expertise: Oral Surgery, Periodontics, Endodontics, Restorative Dentistry, $\mathrm{CBCT}$, Imaging in Dentistry.

We confirm that we have read this submission and believe that we have an appropriate level of expertise to confirm that it is of an acceptable scientific standard.

Author Response 16 Nov 2021

\section{Kelvin Afrashtehfar}

The experienced clinician-scientists and reviewers, Prof. Luca Testarelli and Prof. Rodolfo Reda, are thanked for finding value and expertise in this correspondence comment. 
The reviewers acknowledged that the criticisms found in this work do not represent a conflict of interest; thus, they were considered valid.

Interestingly, there was also an agreement between the reviewers and the author for improved transparency on the conduction and reporting of overview studies.

The reviewers found additional value in having overviews pursuing a formal repository registry and presenting the identification number.

Lastly, the reviewers are acknowledged for comprehensively appraising this work and supporting the publication of this manuscript.

Competing Interests: No competing interests were disclosed.

Reviewer Report 21 July 2021

\section{https://doi.org/10.5256/f1000research.56469.r86654}

(c) 2021 Roqué-Figuls M. This is an open access peer review report distributed under the terms of the Creative Commons Attribution License, which permits unrestricted use, distribution, and reproduction in any medium, provided the original work is properly cited.

\section{? Marta Roqué-Figuls}

${ }^{1}$ Iberoamerican Cochrane Centre, Biomedical Research Institute Sant Pau (IIB Sant Pau), Barcelona, Spain

2 Iberoamerican Cochrane Centre, Biomedical Research Institute Sant Pau (IIB Sant Pau), Barcelona, Spain

3 Iberoamerican Cochrane Centre, Biomedical Research Institute Sant Pau (IIB Sant Pau), Barcelona, Spain

This comment from Afrashtehfar refers to an overview by Sarkis-Onofre et al., 20191 ${ }^{1}$, published in Esthet Restor Dent, which discusses key aspects of systematic reviews in restorative dentistry, focusing on the improvement of the conduct and reporting of these reviews. The author of the comment identifies specific shortcomings of the Sarkis-Onofre et al. overview and formulates some suggestions to improve future methodological quality assessment manuscripts.

As a general thought, this comment would surely be better suited to be published in the original journal, in order to reach the same audience that read the original paper.

The author of this comment is also an author of a review included in Sarkis-Onofre et al. and illustrates his criticisms of their paper with the assessments made to his review. Given this clear conflict of interest, he should be careful in formulating subjective assessments such as "Perhaps Sarkis-Onofre et al. should have dedicated more time to conduct an adequate assessment", or using the terms 'safe' or 'respectful'. 
The author criticises the methods applied by Sarkis-Onofre et al., particularly that a single researcher conducted the study selection and AMSTAR-2 assessment. These criticisms are based on perceived errors in the AMSTAR-2 assessments made to his own review included in SarkisOnofre et al., and on the failure to identify and include in the overview another work he authored (Afrashtehfar et $\mathrm{al}_{\mathrm{l}}, \mathrm{2016}^{2}$ ). While these are undeniable facts and the methods applied in the overview were subpar, it's not clear whether the errors identified are the exception or the norm, nor their impact on the overview conclusions.

He also points out the need for more transparency in the reporting of AMSTAR-2 assessments whenever these challenge personal communications with the original study authors. I fully support the idea to present in an appendix the clarifications about methodology provided in personal communications and the reasons for Sarkis-Onofre et al. to accept or disregard them in each case.

However, there are two instances of unjustified statements made in the comment. First, the author challenges the justification of Sarkis-Onofre et al. for not registering their methodological overview in PROSPERO, arguing that as an overview it could have been registered. However, this fails to acknowledge that methodological overviews that provide no data on patient-relevant outcomes don't verify PROSPERO registration criteria for methodological reviews.

Second, the author assumes that the overview, which updates a previously published overview from different authors, should follow the original overview protocol. But, while any review must have a pre-specified protocol, it's not necessary for an update to follow the protocol of the original review, as that protocol may be inexistent or outdated. What is important is that Sarkis-Onofre et al. do have a protocol available at request.

The author finishes his comment by proposing a list of suggestions for improving future methodological quality assessment manuscripts, mostly already known and common sense. However, the recommendation that AMSTAR-2 be applied by experts in the field rather than research students lacks evidence and is quite debatable.

\section{References}

1. Sarkis-Onofre R, Pereira-Cenci T, Tricco AC, Demarco FF, et al.: Systematic reviews in restorative dentistry: discussing relevant aspects.J Esthet Restor Dent. 31 (3): 222-232 PubMed Abstract I Publisher Full Text

2. Afrashtehfar KI, Ahmadi M, Emami E, Abi-Nader S, et al.: Failure of single-unit restorations on root filled posterior teeth: a systematic review.Int Endod J. 2017; 50 (10): 951-966 PubMed Abstract | Publisher Full Text

Is the rationale for commenting on the previous publication clearly described? Yes

Are any opinions stated well-argued, clear and cogent? Partly

Are arguments sufficiently supported by evidence from the published literature or by new data and results? 
Partly

Is the conclusion balanced and justified on the basis of the presented arguments?

Partly

Competing Interests: No competing interests were disclosed.

Reviewer Expertise: I am a statistician, author of several systematic reviews, and an editor in two Cochrane Review Groups, conducting peer reviews frequently.

I confirm that I have read this submission and believe that I have an appropriate level of expertise to confirm that it is of an acceptable scientific standard, however I have significant reservations, as outlined above.

Author Response 16 Nov 2021

\section{Kelvin Afrashtehfar}

I thank Prof. Roqué-Figuls for supporting the idea of presenting an appendix with methodological clarifications provided in the e-mail exchange between the overview authors (Sarkis-Onofre R, Pereira-Cenci T, Tricco AC, Demarco FF, Moher D, Cenci MS. Systematic reviews in restorative dentistry: discussing relevant aspects. J Esthet Restor Dent. 2019 May;31(3):222-232) and the comment author.

Regarding the overview protocol registration, AMSTAR-2 considers "protocol registered before start of review" as a critical domain. Please refer to Shea BJ, Reeves BC, Wells G, Thuku M, Hamel C, Moran J, Moher D, Tugwell P, Welch V, Kristjansson E, Henry DA. AMSTAR 2: a critical appraisal tool for systematic reviews that include randomised or nonrandomised studies of healthcare interventions, or both. BMJ 2017; 358: j4008. Thus, one would expect that an overview of reviews (or systematic review of systematic reviews) should avoid missing such critical domain that they have assessed in their study where they used systematic reviews as the analytic unit.

Indeed, the author does defend the statement that experienced researchers ideally should apply AMSTAR2 instead of inexperienced research students.

Prof. Roqué-Figuls is thanked for expressing her opinions. However, the comment author did not realize of the reviewer's previous participation in the following publications:

Sáenz Calvo A, Fernández Esteban I, Mataix Sanjuán A, Ausejo Segura M, Roqué M, Moher D. [Metformin for type-2 diabetes mellitus. Systematic review and metaanalysis]. Aten Primaria. 2005 Sep 15;36(4):183-91.

Saenz A, Fernandez-Esteban I, Mataix A, Ausejo M, Roque M, Moher D. Metformin monotherapy for type 2 diabetes mellitus. Cochrane Database Syst Rev. 2005 Jul 20;(3):CD002966.

The author accepts being concerned and kindly requests the reviewer to reconsider her decision about this comment.

The comment author has complied with answering the initial reviewer's comments. Lastly, 
after this participation, the author has no more comments or replies.

Competing Interests: No competing interests were disclosed.

The benefits of publishing with F1000Research:

- Your article is published within days, with no editorial bias

- You can publish traditional articles, null/negative results, case reports, data notes and more

- The peer review process is transparent and collaborative

- Your article is indexed in PubMed after passing peer review

- Dedicated customer support at every stage

For pre-submission enquiries, contact research@f1000.com 